\title{
RECOMENDAÇÕES SOBRE O PROCESSO DE PLANEJAMENTO ESTRATÉGICO
}

$\star$ José Celso Contador

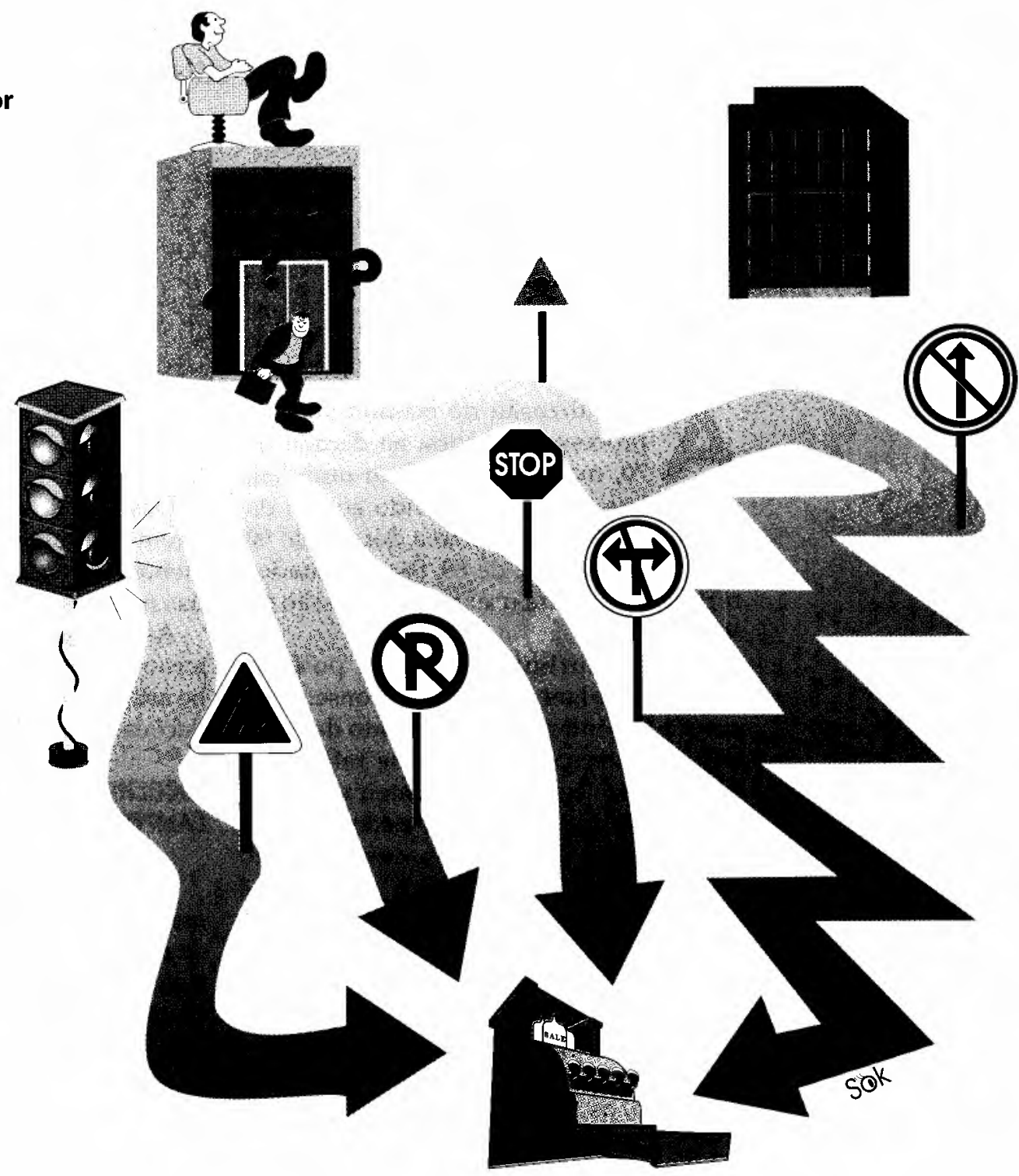

PALAVRAS-CHAVE:

Competitividade, planejamento estratégico, manufatura, mercado, produto, competição, globalização, cadeia produtiva, processo de planejamento, consultoria estratégica, estratégia de manufatura.

\section{KEY WORDS:}

Competitiveness, strategic planning, manufacturing plant, market, product, competition, globalization, production chain, planning process, strategic consulting, strategy of manufacturing.

$\star$ Professor Livre-Docente da Faculdade de Engenharia de Guaratinguetá da UNESP e Consultor Industrial. 


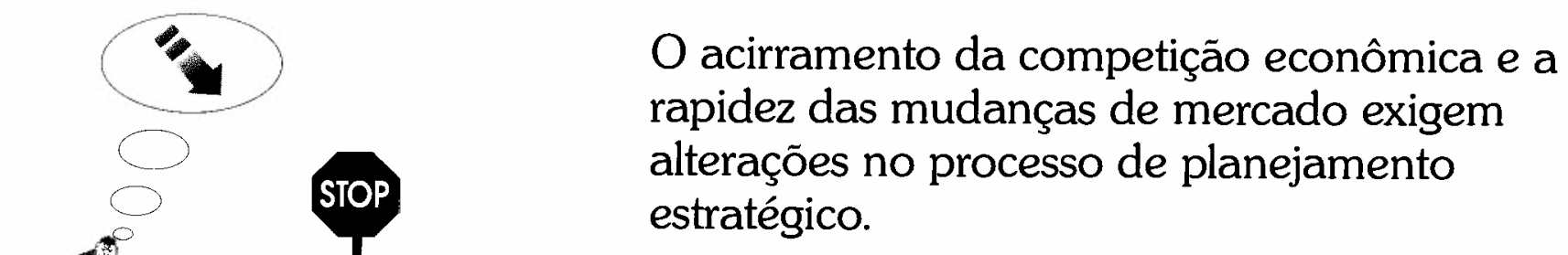

Ver a primeira parte deste artigo: Planejamento estratégico: recomendações sobre os ambientes externo e interno, $R A E$, v. 35, n. 2, mar./abr. 1995

1. ANSOFF, H. Igor. The new corporate strategy. John Wiley \& Sons, 1988

2. CONTADOR, J. Celso. Planejamento estratégico: recomendações sobre os ambientes externo e interno. RAE - Revista de Administracão de Empresas, São Paulo, v. 35, n. 2, p. 43-6, mar./abr. 1995.

3. _. Planejamento estratégico para a competicão dos anos 90. Produção (ABEPRO Associação Brasileira de Engenharia de Produção), Rio de Janeiro, v. 1, n. 2, p. 107-12, mar 1991.

4. PORTER, Michael E. Competitive strategy. New York: The Free Press, 1980.
A globalização da economia, cujo processo se iniciou na década de 70 , mais a nova ordem mundial, que está se instalando devido ao fim da União Soviética, tornarão a década de 90 muito diferente da de 80 . São as grandes turbulências, para usar uma expressão de Igor Ansoff ${ }^{1}$.

É nessa turbulência que a política liberalizante lançou o Brasil. A conseqüência que nos interessa é o aumento da competição internacional, que se reflete na competição dentro das fronteiras nacionais. Essas turbulências já estão atingindo as empresas brasileiras, que precisam se preparar para enfrentar a nova realidade.

Como prevê o nosso modelo para aumentar a competitividade da indústria brasileira de manufatura, essa preparação deve começar pelo planejamento estratégico. Apesar de este ser assunto bastante estudado, as turbulências referidas obrigam à introdução de algumas modificações no planejamento estratégico da empresa. Este é o tema abordado no artigo anterior e neste ${ }^{2}$.

Para tanto, faremos algumas recomendações que, esperamos, orientarão a empresa durante esta década. Elas foram esboçadas no artigo Planejamento estratégico para a competição dos anos 90 , que publicamos na revista Produção da $\mathrm{ABEPRO}^{3}$.

Estas recomendações não substituem os conceitos e as metodologias tradicionais. Pelo contrário, somam-se a eles ou modificam-nos.

Das dezoito recomendações, quatro referem-se ao ambiente externo, sete ao ambiente interno e sete ao processo, agrupadas no quadro 1.

As recomendações sobre o ambiente externo e sobre o interno foram abordadas no artigo anterior (ver nota 2 ); as recomendaçōes metodológicas são objeto deste.

\section{ESCOLHER PRODUTOS, MERCADOS, CAMPOS E ARMAS DA COMPETIÇ̃̃̃}

A metodologia tradicional do planejamento estratégico estabelece a necessidade de se definirem missões, objetivos, filosofias, políticas, estratégias, metas. Mas, fundamentalmente, preocupa-se em escolher os produtos com os quais a empresa competirá e os mercados onde atuará.

Atualmente, à seleção dos produtos e dos mercados somam-se outras duas decisões basilares: a escolha dos campos e das armas da competição.

Se os autores dissertam longamente sobre a eleição dos mercados de atuação, silenciam quanto à dos campos da competição. Quem toca neste tema é Michael Porter, em Competitive strategy, mas o faz de forma superficial ${ }^{4}$.

Nós o fazemos de forma enfática: para os dias atuais, tão importante quanto selecionar produtos e mercados é escolher 
os campos onde a empresa irá competir e as armas que irá utilizar.

\section{Armas da competição}

Os campos da competição são um atributo de interesse do comprador, como preço e qualidade do produto. A arma da competição é o meio que a empresa utiliza para obter vantagem competitiva num campo, como qualidade no processo e produtividade, e não apresenta interesse para o comprador: Esses dois conceitos, devido à sua importância, precisam ser esclarecidos.

A propósito das estratégias competitivas, é comum ouvir-se ou ler-se: "Esta empresa compete em preço; aquela, erm marketing". "A empresa tal compete em qualidade de produto; a outra, em produtividade." "A primeira tem grande variedade de modelos, mas a segunda tem grande rapidez de fabricaçāo".

Com essas expressōes, pretende-se caracterizar um atributo competitivo de uma empresa. Mas, analisando-as, é possível perceber que são de natureza diferente.

Uns atributos interessam ao comprador: preço, qualidade do produto e variedade de modelos, para ficar restrito ao exemplo. Outros não, como marketing, produtividade, rapidez de fabricação.

Enfocando por esse prisma, diferenciamos os campos da competição das armas da competição. (Para maiores detalhes, ver notas 19 e 20.)

Se os campos apresentam interesse, as armas não interessam ao consumidor. Em nada aproveita saber se a empresa opera com alta ou com baixa produtividade (muitos não sabem nem o que é produtividade); interessa, sim, o preço do produto. $O$ comprador não toma conhecimento do índice de rejeição; interessa-se, sim, pela qualidade do produto que adquire.

Os autores, mesmo os mais consagrados, não discernem campo de arma da competição. Tratam-nos indistintamente como estratégias. Ora, sendo a estratégia um meio para se atingir um objetivo e sendo os objetivos hierarquizados, acaba-se tendo que "uma estratégia é um meio para alcançar outra cstratégia", o que sem dúvida causa dubiedade. Para eles, só como exemplo, produtividade e competiçảo em custo são estratégias; para nós, produtividade é uma arma para se concorrer no campo da competição em custo. Nossa

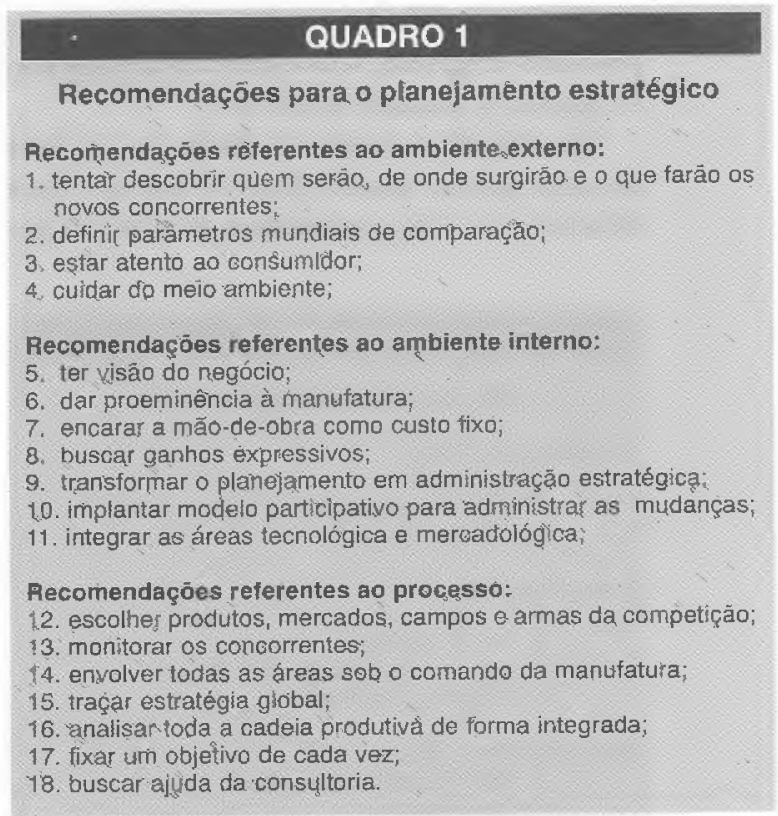

concepção elimina a ambigüidade, e, por isso, entendemo-la como uma contribuição importante.

É importante, para a empresa, distinguir os meios dos fins, pois uma mesma arma serve para competir em mais de um campo, e para competir em um campo são necessárias várias armas. Assim, é necessário haver qualidade no processo -.. uma arma - quer a empresa deseje competir em preço, quer em qualidade do produto. Se a empresa desejar competir em variedade de produtos - um campo - , precisa de várias armas: troca rápida de ferramentas, qualidade no processo, qualidade nas matérias-primas e componentes, produtividade, flexibilidade na manufatura. Como a empresa é um sistema com forte interação entre todos os seus fatores, os campos e as armas podem confundir-se. Como clareza de raciocínio é um elemento facilitador em qualquer área, julgamos relevante estabelecer a nítida diferença entre campo e arma.

Além de conceituá-los, é necessário explicitar os campos onde a indústria brasileira de manufaturados pode competir.

Identificamos quinze diferentes campos genéricos de competiçāo, que podem ser agregados em cinco grupos, como mostra o quadro 2 .

\section{O pentastilo armado da competitividade}

Edwards Deming ${ }^{5}$ expôs, no Japão do início da década de 50, os conceitos do
5. WALTON, Mary. O método Deming de administraçāo. Rio de Janeiro: Marques-Saraiva, 1989. 
binômio qualidade-produtividade. Os japoneses erigiram sobre ele sua indústria. $\mathrm{E}$, agora, o mundo adota-o.

Qualidade e produtividade dependem de uma grande quantidade de fatores. Três deles são tão importantes e de uso tão ge-

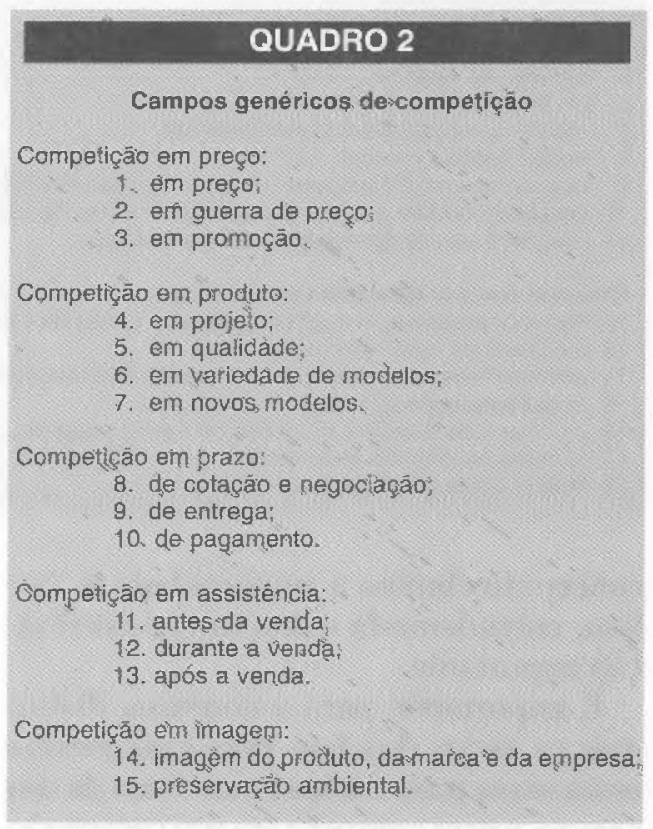

ral que, para chamar a atençāo, é conveniente elevá-los da categoria de fator para a de armas - são eles: tecnologia, estoque reduzido e pessoal capacitado, motivado e participativo. Essas cinco armas equivalem, pois, figurativamente, às cinco colunas do pórtico que sustenta a competitividade: o pentastilo da competitividade.

O pentastilo armado da competitividade representa as cinco armas de uso generalizado. Para serem competitivas, todas as empresas precisam em maior ou menor grau, dependendo do campo de competição escolhido, operar com produtividade, qualidade no processo, tecnologia e estoques reduzidos, e possuir pessoal capacitado e participativo, que sāo as cinco armas do pentastilo armado da competitividade. (Para maiores detalhes, ver nota 20 ).

Outras armas, obviamente, são necessárias, mas essas cinco sāo as mais gerais

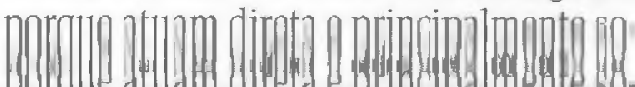
polque atlatim wede primcipalnenteso. bre o custo. E o custo é importante nẫo só para as empresas que pretendem competir em preço, como também para as que concorrem num dos campos da diferenciação, pois, como afirma Michael Porter, uma empresa diferenciada deve possuir uma paridade ou uma proximidade de custos em relação a seus concorrentes para não perder a vantagem adquirida ${ }^{6}$.

Dezenas de armas estão à disposição da empresa. Mas nāo é objetivo deste artigo tratar delas.

O planejamento estratégico dentro do modelo de competitividade

Nosso modelo para aumentar a competitividade da indústria brasileira de manufaturados ${ }^{7}$ é um modelo de produtividade estratégica porque tem como objetivo dar à empresa alta produtividade somente naquelas áreas que propiciarão vantagem competitiva. É, pois, um modelo seletivo e objetivo: mostra onde e como a empresa deve atuar para alcançar determinada vantagem, ao contrário de outros modelos, que acabam por dispersar esforços em diversas áreas. O primeiro grupo de medidas do modelo refere-se ao planejamento estratégico, que deve tomar quatro decisões fundamentais: selecionar os produtos com os quais a empresa irá concorrer; escolher os mercados onde irá atuar; eleger os campos da competição; e assinalar as armas a utilizar. Dessas quatro decisões, as três primeiras sāo complexas; mas a quarta é simples, pois decorre do campo eleito: para cada campo, existem algumas armas mais adequadas. Aqui reside a seletividade do modelo, uma das suas grandes vantagens: as dezenas de armas disponíveis ficam reduzidas a algumas, ou seja, para a empresa tornar-se competitiva no campo escolhido, basta adquirir alta efetividade em apenas algumas armas e não em todas.

\section{Escolha dos campos da competiçăo}

Das quatro decisões fundamentais do planejamento estratégico - produto, mercado, campos e armas - , é necessário discorrer apenas sobre a escolha dos campos, pois, sobre a seleção de produtos e de mercados, a bibliografia é farta. E sobre a de armas, basta comentar que é na sua utilização que se encontra a grande dificulda-

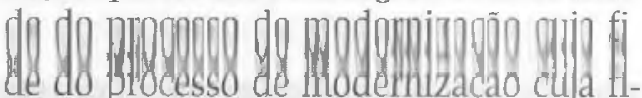
nalidade seja aumentar o nível de competitividade da empresa. Entretanto, se a utilização das armas encerra muitas difi- 
culdades, sua escolha é relativamente simples, pois, apesar de existirem dezenas de armas à disposição da empresa, são poucas as mais adequadas a cada campo.

A empresa deverá eleger um ou poucos campos onde irá competir. A primeira decisão é optar entre competir em custo ou competir nos outros campos (produto, prazo, assistência ou imagem).

Competir nesses campos significa diferenciar-se dos concorrentes. Geralmente, para diferenciar-se, a empresa incorre em custos extras na expectativa de que o comprador esteja disposto a pagar um plus pelo produto ou serviço diferenciado. Portanto, competir em preço e em algum campo da diferenciação é, na maioria das vezes, incompatível. Não o será quando a empresa estiver no quarto quadrante de Gilbert - diferenciação alta e produtividade alta $^{8}$. Mas raras são as empresas nessa situação - no Brasil não conhecemos nenhuma. Como observa Francisco Gracioso, nem as empresas automobilísticas japonesas atingiram ainda esse quarto quadrante.

Apesar de não identificar os campos de competição com a clareza e a ênfase dadas por nós, Michael Porter, tanto em Competitive strategy como em Competitive advantage ${ }^{10}$, analisa a concorrência em custo em diferenciação, sem especificar exatamente quais sejam os campos da diferenciação.

Para ele, uma empresa que tenta algumas estratégias mas não alcança nenhuma está no meio-termo, e não possui vantagem competitiva alguma. Essa posição é geralmente a receita para o desempenho abaixo da média, pois o líder em custo e as empresas diferenciadas sempre estarão mais bem posicionados para competir. Uma empresa no meio-termo só terá bons lucros se a estrutura de sua indústria for muito favorável ou se os concorrentes também estiverem no meio-termo. Ficar no meio-termo é, na maioria das vezes, manifestaçāo da relutância da empresa em decidir como competir.

Reduzir custos, diz Porter, nem sempre implica sacrificar a diferenciação. E reduzir custos não significa obter vantagem em custo, pois quando a empresa estiver enfrentando um concorrente que também luta pela liderança no custo chegará ao ponto em que uma maior redução dos cus-

\section{Acompanhar os movimentos dos concorrentes torna-se mais e mais importante à medida que cresce a disputa entre as empresas. Mas, não é preciso fazer espionagem industrial.}

tos exigirá sacrifícios na diferenciação. É nesse ponto que essas estratégias se tornam incompatíveis, e a empresa precisa escolher uma ou outra.

Se a empresa conseguir obter simultaneamente liderança em custo e em diferenciação, as recompensas serão grandes porque os benefícios somam-se: a diferenciação conduz a preços-prêmio, ao mesmo tempo que a liderança no custo significa custos menores. Existem três situaçōes onde a empresa pode conseguir simultaneamente liderança em custo e em diferenciação:

- os concorrentes estão no meio-termo: nesse caso, ninguém está suficientemente bem posicionado para forçar a empresa para o ponto em que custo e diferenciação se tornam inconsistentes;

- o custo é fortemente afetado pela participação de mercado e não pelo projeto do produto, pelo nível de tecnologia, pelo serviço oferecido ou por outros fatores: nesse caso, as vantagens de custos obtidos pela alta participação de mercado permitem à empresa onerar os custos de outros setores, ou a alta participação reduz o custo da diferenciação em relação aos concorrentes;

- a empresa é pioneira em uma importante inovação: a implantação de nova tecnologia de produção, ou de um sistema de informações para logística, ou de um sistema computadorizado de projeto de produto, ou até o estabelecimento de relações cooperativas com fornecedores, pode permitir a redução de custo e ao mesmo tempo intensificar a diferenciaçāo, desde que a empresa seja a única detentora dessa inovação.

Finalmente, Porter recomenda: "Uma empresa sempre deve buscar agressivamente to-
8. GILBERT, Xavier. Industry analysis, development of strategies to respond to competitive forces. Lausanne, Suiça: IMEDE - Institute pour le Développement de L'Entreprise, 1981.

9. GRACIOSO, Francisco. Planejamento estratégico orientado para o mercado. São Paulo: Atlas, 1987.

10. PORTER, Michael E. Competitive advantage. New York: The Free Press, 1985. 
11. FULD, Leonard. Criar um sistema de monitoramento dos concorrentes. Gazeta Mercantil, São Paulo, 19 jun. 1991. das as oportunidades de redução de custo que não sacrifiquem a diferenciação. E sempre deve buscar todas as oportunidades de diferenciação que não onerem os custos. Além desse ponto, precisa escolher uma das duas estratégias. Uma estratégia não leva a um desempenho acima da média a menos que seja sustentável fren te aos concorrentes".

\section{MONITORAR OS CONCORRENTES}

Acompanhar os movimentos dos concorrentes é importante à medida que cresce a disputa entre as empresas.

A obtenção de informações sobre os concorrentes não implica necessariamente espionagem, pois geralmente existem em razoável quantidade dentro da própria empresa ou podem ser obtidas no curso normal do trabalho. Cabe à empresa, isto sim, manter um sistema de coleta, seleção, classificação, armazenamento, restituição e distribuição dessas informaçōes.

Leonard Fuld ${ }^{11}$, pioneiro em competitor intelligence, indica as principais áreas da empresa que possuem ou podem obter informações valiosas sobre os concorrentes: vendas, marketing, compras, pesquisa e desenvolvimento, crédito, assistência técnica, distribuição, relações governamentais, jurídica, recursos humanos e biblioteca.

Os vendedores são a melhor fonte de informaçōes sobre os concorrentes e suas atividades de marketing. Nos contatos com os clientes, os vendedores acabam tomando conhecimento da forma de atuação, dos preços, das promoções e das estratégias dos concorrentes.

A área de publicidade coleciona cópia dos anúncios dos concorrentes, inclusive gravando anúncios de rádio e televisão, que divulgam as características dos novos produtos e dos temas de marketing.

Os compradores podem obter junto a fornecedores comuns informações detalhadas sobre as necessidades dos concorrentes.

O pessoal de pesquisa e desenvolvimento, por participar abertamente do intercâmbio de pesquisas científicas, e por utilizar os mesmos bancos de dados de seus colegas da empresa concorrente, é fonte preciosa de informações muito antecipadas.

O departamento de crédito dispōe freqüentemente de informaçōes financeiras.

O pessoal da assistência técnica, nos seus contatos com os clientes, fica sabendo das características, dos defeitos, das deficiências operacionais, das inovações e das vantagens dos produtos novos.

O pessoal da distribuição provavelmente tem muitas informaçōes a respeito dos custos de transporte, capacidade dos armazéns, nível de estoque dos concorrentes.

O pessoal da assessoria de relações governamentais, que sabe como se movimentar nos diversos órgãos públicos, tem valiosíssimas informações devido à sua participação em reuniões em que são discutidos o setor em geral e os concorrentes em particular.

O departamento jurídico acompanha as alterações de normas governamentais, sabe quando um concorrente está envolvido em litígio grave e geralmente analisa os pedidos de concessão de patentes aos concorrentes. (A Hewlett-Packard consegue as melhores informações sobre a IBM em seu departamento jurídico.)

O departamento de recursos humanos sabe quais funcionários já trabalharam para os concorrentes, e estes podem constituir preciosa fonte de informações. $O$ departamento provavelmente tem cópia dos contratos feitos pela empresa e pelos concorrentes com os sindicatos, que dão informações inclusive sobre os custos da mão-de-obra, e observa os anúncios publicados à procurà de funcionários.

A biblioteca é uma grande fonte centralizada de informações. Muitos gerentes se surpreendem com a quantidade de livros, revistas especializadas, boletins, relatórios anuais, recortes de jornal sobre o setor e os concorrentes, disponíveis na biblioteca de sua empresa.

Como se constata, inúmeras são as áreas que dispõem ou podem dispor de informações sobre a concorrência. Portanto, para a empresa organizar um sistema de inteligência, Fuld faz quatro recomendações: decidir quais concorrentes devem ser observados, já que nem todos despertam interesse estratégico; nomear uma pessoa experiente e respeitada da empresa para ser o responsável pela supervisão do monitoramento e pela coordenação das informações, capaz de avaliar sua importância; desenvolver e implantar um siste- 
ma centralizado de informações que inclusive as remeta rapidamente à área da empresa que poderá ser beneficiada pela informação oportuna; e encorajar todos os funcionários, desde a alta administração até os motoristas de caminhão, a contribuir regularmente com suas observações a respeito das atividades dos concorrentes, pois o conhecimento que podem obter tem muitas vezes uma antecedência de várias semanas sobre os relatos que aparecem na imprensa especializada ${ }^{12}$.

\section{ENVOLVER TODAS AS ÁREAS SOB O COMANDO DA MANUFATURA}

Que o processo de planejamento estratégico deve envolver todas as áreas da empresa, é consensual. Para dar competitividade à empresa, é necessário que todas as suas forças sejam canalizadas no mesmo sentido. Fayol já o escrevia em 1916 com outras palavras ${ }^{13}$.

O que se discutirá aqui é a quem cabe a coordenação, ou melhor, o comando do processo.

Analisando a visão de Gluck et al. sobre a evolução do planejamento estratégico, é possível concluir sobre a importância relativa que as empresas, no caso as norte-americanas que o introduziram, davam às suas diversas áreas.

Assim, na fase do planejamento financeiro, pelos idos dos anos 50, o comando cabia à área financeira da empresa, que trabalhava quase autonomamente e controlava a todos para que o orçamento fosse cumprido; na fase do planejamento de longo prazo, que predominou nos anos 60 , a introdução de análises e projeções de mercado para prever o futuro fez com que o comando do processo de planejamento passasse a ser dividido entre as áreas de finanças e de marketing; na fase do planejamento estratégico voltado para o ambiente externo, que preponderou na década de 70, o comando ficou com a área de marketing; na fase da administração estratégica, que surgiu na década de 80 , para conseguir resolver os problemas de implantação, o comando cedeu lugar à coordenação exercida pela área de marketing ou por assessorias especializadas, dependendo do nível do planejamento (planejamento de produto/mercado, da unidade empresarial, dos recursos comuns a vá- rias unidades e da empresa como um todo).

E para os anos 90? Para os anos 90, propomos que o comando do processo de planejamento estratégico fique com a manufatura. Porque é a manufatura que produz qualidade; é a manufatura que produz custo baixo; é a manufatura que produz menor prazo de entrega; é a manufatura que produz flexibilidade para a troca de produto; é a manufatura que viabiliza a diversificação de produtos e o lançamento de novos produtos. Enfim, é a manufatura que dará competitividade à empresa; ou melhor, que dará agilidade competitiva para a empresa mudar rapidamente. Não é a área de marketing nem a de finanças. Obviamente, todas as areas (marketing, finanças, pesquisa e desenvolvimento, suprimentos, recursos humanos, engenharia de produto, engenharia de processo, controle de qualidade etc.) precisam participar para poder canalizar seus esforços no sentido decidido. Mas o comando deve estar com a manufatura.

Dar o comando do processo de planejamento ao pessoal da produção é u ${ }^{m}$ ‘a das formas à disposição da empresa para demonstrar, com atos, a importância que atribui à manufatura, na luta pela competitividade.

\section{TRAÇAR ESTRATÉGIA GLOBAL}

Para alcançar melhorias significativas, a empresa precisa traçar uma estratégia que envolva todas as suas áreas. Dessa estratégia brotarão inúmeros programas setoriais, mas articulados entre si.

Essa recomendação é resultado da observação da realidade: ações isoladas, como aplicar só MRP (Material Requirement Planning ou Planejamento das Necessidades de Materiais), ou só JIT (Just-in-Time ou Produção Apenas-a-Tempo), ou só TQC (Total Quality Control ou Controle da Qualidade Total), propiciam efeitos não muito satisfatórios.

O nosso modelo para aumentar a competitividade da indústria brasileira de manufatura tem a característica de estratégia geral no que tange à produtividade. Mas, para que a estratégia seja efetivamente global, esse modelo precisa ser acompanhado de planos estratégicos nas áreas de marketing, finanças, suprimentos, engenharia de produto e pesquisa e desenvol-
12. Idem, ibidem.

13. SILVA, Benedicto. Taylor e Fayol. Rio de Janeiro: Fundação Getúlio Vargas, 1974. 
vimento. A necessidade de estratégia global consta dos compêndios de planejamento estratégico. Portanto, sua menção aqui seria dispensável. Mas, devido à sua importância, resolvemos reforçá-la.

Exemplo de estratégia global é dado pela Embraco (Empresa Brasileira de Compressores), inaugurada em 1971, em Joinville, e controlada pelo Grupo Brasmotor desde 1977. Criada para fabricar compressores herméticos para refrigeradores, que pudessem substituir, com a mesma qualidade, os modelos importados, hoje é o segundo maior produtor mundial de compressores herméticos, atendendo nada menos que $10 \%$ do mercado mun-

\section{A manufatura era a ārea proeminente na Era da Produção em Massa. Depois foi a vez da área de finanças, que passou 0 bastão para a de marketing. Nos dias atuais, a bola está de novo com a manufatura.}

14. DIRIGENTE INDUSTRIAL EMBRACO, o Atleta dos Compressores. São Paulo: Visão, v. 30, n. 7, p. 28-31, abr. 1989.

15. GRACIOSO, Francisco. Op. cit.

16. Idem, ibidem.

17. Idem, ibidem.

18. RIES, Al, TROUT, Jack. Marketing de guerra. São Paulo: McGraw-Hill, 1986.
Embraco firmou acordo com a conceituada Danfoss, da Dinamarca, empresa pioneira no desenvolvimento de compressores herméticos para refrigeração. Hoje já dispõe de equipe de pesquisa e desenvolvimento altamente especializada, que conta inclusive com detentores de Ph.D., mantém convênios com universidades brasileiras e estrangeiras e investe $2 \%$ de seu faturamento em pesquisa e desenvolvimento de novas tecnologias. Seu novo compressor, o EM, comprova que o esforço em pesquisa e desenvolvimento dá resultados altamente satisfatórios: dotado de tecnologia totalmente nacional, é mais silencioso e apresenta uma redução de $10 \%$ nas dimensões físicas, de $15 \%$ no peso e de $18 \%$ no consumo de energia, quando comparado com o modelo anterior, o PW. Em rendimento, o novo compressor é reconhecidamente superior ao modelo dinamarquês ${ }^{17}$.

Para assegurar o segundo, o terceiro e o quarto pontos (qualidade, preço e prazo), a Embraco adotou uma política de verticalização assentada no binômio qualidade-produtividade. Depende muito pouco de fornecedores de componentes, pois funde suas peças, constrói suas ferramentas e fabrica inclusive os motores elétricos. Graças às instalações e equipamentos modernos, como máquinas transfer para usinagem (capazes de realizar mais de cinqüenta operações sucessivas) e linha de montagem robotizada (que faz também o registro dos resultados dos testes), consegue alta produtividade e alta qualidade. A qualidade é controlada por 1.200 testes realizados diariamente nos seus laboratórios metalográfico, químico, físico, elétrico e acústico.

Esses quatro pontos (tecnologia, qualidade, preço e prazo) deram à Embraco paridade com os cinco maiores produtores mundiais (Matsushita do Japão, Danfoss da Dinamarca, Tecumseh dos Estados Unidos e Necchi e Aspera da Itália). Mas, para disputar agressivamente um mercado mundial já estabilizado, seria necessário oferecer algumas vantagens exclusivas. Essa diferenciação, a Embraco encontrou nos aspectos comerciais, consubstanciados nos pontos quinto, sexto e sétimo (assistência técnica, assessoramento tecnológico e apoio promo(cional $)^{18}$. 
Com esta estratégia, a Embraco, empresa nova de um país sem tradição tecnológica e com imagem desgastada, conseguiu tornar-se o segundo produtor mundial de compressores herméticos, atrás apenas da japonesa Matsushita. E, naturalmente, essa estratégia, almejando o mercado internacional, deu à ela uma vantagem inatingível pelos outros fabricantes no mercado doméstico.

\section{ANALISAR TODA A CADEIA PRODUTIVA DE FORMA INTEGRADA}

Para ser possível atender de forma correta as recomendações anteriores de traçar estratégia global e decidir os campos onde competir, é necessário analisar toda a cadeia produtiva de forma integrada.

Começando pelo recebimento, armazenamento e distribuição dos insumos; passando pela fabricação, montagem e embalagem dos produtos; indo para armazenamento, faturamento e distribuição dos produtos; alcançando a instalação, treinamento e assistência técnica ao cliente; valorizando a propaganda e a força de vendas; e cuidando para que tudo isso aconteça por meio da pesquisa e desenvolvimento de tecnologia e de produto, de desenvolvimento dos recursos humanos, enfim, por meio da administração da empresa.

Parece óbvio que assim seja. Mas só o é depois de dito. Em uma fábrica de produtos extrudados, era comum o caminhão já carregado de perfis metálicos ficar horas na portaria à espera da emissão da nota fiscal. Ou seja, a expedição era feita em menor tempo do que o faturamento. E essa fábrica é uma multinacional! E considerada bem organizada. Numa época em que os clientes procuram trabalhar com estoques baixos, as horas perdidas pelo caminhão, à espera do faturamento, podem representar queda na capacidade competitiva da empresa.

Porém, deve-se ir mais além: é necessário analisar toda a cadeia produtiva, dos fornecedores aos clientes. A integração de toda a cadeia produtiva permitirá ganhos insuspeitáveis.

Essa recomendação não é nova. Michael Porter tratou-a profunda e adequadamente em seu segundo livro, Competitive advantage. Mencionamo-la devido à sua importância. Tanto o é que o ponto alto desse livro, a grande inovação em relação ao primeiro, Competitive strategy, é exatamente o tema cadeia de valores.

\section{FIXAR UM OBJETIVO DE CADA VEZ}

Levar a bom termo um programa de melhorias exige uma concentração maciça de esforços. O general prussiano Karl von Clausewitz, que inspirou Ries e Trout a escreverem Marketing de guerra ${ }^{20}$, já dizia: "Mantenha sempre suas forças concentradas e na melhor forma possível. Essa é a idéia principal. O maior número possivel de soldados deve ser posto em ação no ponto decisivo". Para evitar dispersão, então, deve-se fixar um objetivo de cada vez para cada setor da empresa.

Como para atingir um objetivo são necessárias muitas ações, o plano de melhorias deve fixar metas setoriais, que por sua vez são compostas por várias ações. Pela agregação dos resultados de cada ação, alcança-se a meta; pela dos resultados de cada meta, atingese o objetivo.

Além da concentração de esforços, há outra razão para a recomendação de um objetivo de cada vez: um objetivo, pode-se medir e cobrar diariamente; dez objetivos, torna-se muito mais difícil. E se não houver medida e a conseqüente cobrança ou reconhecimento, a motivação e a mobilização caem.

Um exemplo para elucidar: "Neste ano, o objetivo é aumentar em $30 \%$ a produtividade".

O plano de melhorias deve estabelecer então metas setoriais, que, uma vez atingidas, farão com que o objetivo seja alcançado. Cada setor produtivo terá, por exemplo, três metas a cumprir: produtividade da mão-de-obra, da máquina e de materiais. Os setores de manutenção, ferramentaria e suprimentos também terão
19. CONTADOR, J. Celso. Campos da competição. Revista de Administração da USP, São Paulo, v. 30 , n. 1, jan./mar. 1995.

20. Armas da competição. Revista de Administração da USP, São Paulo, v. 30, n. 2, abr./ jun. 1995. 
suas metas, bem como os de marketing, controle de qualidade, engenharia de produto, engenharia de processo etc.

Para cumprir sua meta de aumentar a produtividade da máquina, cada setor produtivo precisará desencadear inúmeras ações. E os resultados delas serão medidos por indicadores do tipo: horas paradas classificadas por motivo, horas improdutivas classificadas por motivo, eficiência e produtividade de cada máquina.

Para cumprir sua meta de aumentar a produtividade do material, cada setor precisará desencadear inúmeras ações: o setor de suprimentos necessitará negociar com os fornecedores para diminuir o preço e o estoque de matérias-primas e componentes; o setor de PCP preocupar-se-á em programar a produção de forma mais ajustada à demanda para diminuir o estoque de produtos acabados; os setores produtivos cuidarão de reduzir o tamanho do lote de fabricação e olead time, que por sua vez dependem da forma como é programada a produção e como se comportam os gargalos. Não é tarefa fácil. Os resultados dessas ações serão medidos por indicadores do tipo: estoque de matérias-primas, de componentes, de materiais em processo, de materiais auxiliares, de produtos acabados; consumo de matérias-primas, componentes e materiais auxiliares; índice de retalho, de rejeição interna, de devolução e de retrabalho.

$O$ primeiro caso, aumento da produtividade da máquina, representa uma preocupação antiga, na linha taylorista. O segundo caso, aumento da produtividade do material, representa uma preocupação mais recente, na linha de redução dos estoques.

Essas duas preocupações são necessárias mas insuficientes para a competitividade atual. São necessárias porque atuam sobre o custo, reduzindo-o. São insuficientes porque abordam apenas parte do todo, e a visão sistêmica da empresa exige uma medida global da produtividade. Essa medida global precisa incluir o cliente. Se o cliente não comprar o produto ou não quiser pagar o preço pedido, a produtividade total da empresa será baixa, por mais alta que seja sua produtividade operacional. As características, as funções e a qualidade do produto, ou seja, o valor que o produto tem para o comprador, de- terminam o preço e o volume de vendas; em outras palavras, determinam o faturamento da empresa. Portanto, a avaliação global da produtividade para os dias de hoje assemelha-se à lucratividade, medida pela relação entre faturamento e custos.

Esse exemplo sobre a hierarquização de objetivos, metas e ações esclarece a recomendação: "Fixar um objetivo de cada vez, cuidar de uma ação de cada vez".

\section{BUSCAR AJUDA DA CONSULTORIA}

Implantar um processo de planejamento, elaborar um plano estratégico, efetivar as mudanças e colocar em prática a administração participativa são tarefas complexas e de grande dificuldade. Muitos são os enfoques conceituais, diversas são as metodologias, inúmeras são as técnicas passíveis de se adotar. De todas as alternativas de enfoques, metodologias e técnicas, há sempre uma mais adequada à empresa em questão.

As empresas que tentarem executar essas tarefas sem o conhecimento técnico necessário dificilmente terão sucesso. Por essa razão, recomendamos que a empresa recorra a especialistas que tenham arcabouço teórico e experiência.

Náo obstante o gigantesco esforço para ganhar competitividade deva ser feito dentro da empresa, pelos seus funcionários, de maneira participativa, a consultoria externa pode desempenhar um papel muito importante para auxiliar a empresa, porque:

- tem conhecimento do ambiente externo;

- domina os conceitos, as metodologias e as técnicas;

- tem experiência anterior que indica o caminho melhor, mais seguro e mais rápido;

- é treinada para ajudar as pessoas a fazerem pela primeira vez.

Por todas essas razões, a consultoria consegue bons resultados em curto espaço de tempo, o que amortiza rapidamente seu custo. É, pois, recomendável que a empresa vá buscar ajuda da consultoria. $\square$

\section{5}

